\title{
Proračun posuda sa vazduhom za zaštitu cevovoda od hidrauličnog udara
}

$\mathrm{P}$

osude sa komprimovanim vazduhom mogu na efektivan način da umanje pojavu prekomernog povišenja i smanjenja pritiska usled hidrauličnog udara u industrijskim cevovodima. U radu je prikazana pojednostavljena procedura za proračun zapremine posude koju zauzima vazduh i ukupne zapremine posude. U radu su date preporuke za pravilan izbor dimenzija ulaznog i izlaznog cevnog priključka na posudi čime se može minimizirati njena zapremina.

\section{UVOD}

Brze promene protoka u cevovodu, izazvane brzim zatvaranjem zaustavnih ventila ili naglim prestankom rada pumpe, dovode do oscilacija pritiska u sistemu što se ispoljava nizom udara u zid cevi. Udari se mogu zapaziti i po zvuku i po opterećenju cevi, a njihovo dejstvo može da izazove i havariju cevovoda.

$\mathrm{U}$ ovom radu je prikazana pojednostavljena procedura za proračun zapremine posude sa vazdušnim jastukom za zaštitu cevovoda od hidrauličnog udara. Takođe su date preporuke za pravilan izbor dimenzija ulaznog i izlaznog cevnog priključka na posudi.

\section{POJAVA HIDRAULIČNOG UDARA}

Niz pojava koje nastaju u cevovodu zbog nagle promene brzine strujanja ruski naunik Žukovski nazvao je hidrauličnim udarom. Žukovski je prvi (1889. godine) teorijski opisao pojavu hidrauličnog udara, odnosno, postavio diferencijalne jednačine i našao njihova rešenja. Zbog velikih promena pritisaka do kojih dolazi pri hidrauličnom udaru, mora se uzeti u obzir i stišljivost tečnosti i elastičnost cevovoda. Kretanje tečnosti za vreme hidrauličnog udara je oscilatorno, a zahvaljujući postojanju trenja zbog hrapavosti cevovoda i lokalnih otpora oscilacije se prigušuju i tokom vremena iščezavaju [1].

Hidraulični udar (eng. Water Hammer, Hydraulic Surge) definiše se još kao prelazna pojava koja se javlja usled nagle promene brzine fluida uzrokovane posledicama ljudskog uticaja ili radom samog cevovodnog sistema. Javlja se usled naglog uspostavljanja ili zaustavljanja protoka fluida, ali takođe i nagle promene smera strujanja fluida. Pojava hidrauličnog udara najčešće se povezuje sa naglim zatvaranjem ventila na cevovodu ili prestankom rada pumpe. Kada prelazne pojave iščeznu, uspostavlja se novo stacionarno stanje. Opšte je poznato da ukoliko na cevovodu nije primenjen neki od zaštitnih sistema ova pojava može naneti veliku štetu na samom cevovodu ili na uređajima koji su deo sistema [2].

Odgovarajući tip zaštite od hidrauličnog udara zavisi od konfiguracije cevovoda i režima strujanja fluida koji se transportuje. Usisni deo cevovoda je moguće zaštititi nepovratnim ventilom pod uslovom da se može tolerisati određen nivo vakuuma u sistemu. Daleko efikasniji način za sprečavanje prekomernog podpritiska ili nadpritiska u sistemu je primena posuda sa vazdušnim jastukom koje se u literaturi još nazivaju vazdušne komore, posude za hidraulični udar, pneumatske posude ili hidrofori [3]. Sistem funkcioniše na taj način da se prilikom pojave prekomernog nadpritiska u cevovodu fluid preliva iz cevovoda u posudu pri čemu se vazduh u posudi sabija. U slučaju smanjenja pritiska u cevovodu fluid se iz posude preliva u cevovod pri ekspanziji vazduha u posudi.

Bez obzira da li je hidraulični udar izazvan naglim smanjenjem ili povećanjem pritiska u instalaciji, na hidrodinamičko stanje tečnosti najviše utiču inercijalne i sile pritiska. Kod dugih cevovoda moraju se uzeti u obzir i otpori usled trenja i lokalni otpori koji utiču na prigušenje intenziteta hidrauličnog udara.

Hidraulični udar je najizraženiji u slučaju cevovoda sa malim otporom trenja kao i u slučajevima gde je inercija rotacionog kretanja radnog kola pumpe zanemarljiva tako da je zaustavljanje protoka fluida trenutno. Drugi tip hidrauličnog udara koji nastaje kod zatvaranja zaustavnih ventila na kraju potisnog dela cevovoda. Ovaj tip hidrauličnog udara je uobičajeno manje intenzivan zbog toga što se ventili, naročito na cevovodima velikih prečnika, zatvaraju u određenom vremenskom intervalu. Pojava vakuuma u sistemu usled hidrauličnog udara je naročito nepovoljna zbog mogućnosti isparavanja radnog fluida u cevovodu i formiranja parnog čepa.

Posude sa komprimovanim vazduhom sprečavaju pojavu vakuuma bolje od drugih tipova zaštitnih uređaja, jer omogućavaju održavanje nadpritiska duž cele trase cevovoda u svim fazama pokretanja, rada i zaustavljanja pumpe. Ovo se postiže potiskivanjem fluida iz posude u cevovod posredstvom komprimovanog vazduha [3]. Kao što je rečeno, otpori strujanju usled trenja i lokalnih otpora utiču na smanjenje brzine proticanja fluida i na taj način prigušuju oscilacije koje se javljaju usled hidrauličnog udara. Efekat prigušenja protoka je u ovom slučaju poželjan naročito kod proticanja fluida iz cevovoda u posudu gde u slučaju odsustva prigušnog elementa ili kratke linije cevovoda može doći do prekomernog povećanja pritiska u posudi.

Primer dobre prakse je da se na potisnom vodu cevi (između 
pumpe i posude za hidraulični udar) ugradi nepovratni venil kako bi se sprečilo povratno strujanje fluida kroz pumpu [3].

Pojava hidrauličnog udara se opisuje jednačinom održanja količine kretanja za stišljive fluide. Kako je u pitanju nestacionarna nelinearna parcijalna diferencijalna jednačina njeno rešavanje je moguće jedino primenom numeričkih metoda. Za potrebe analize hidrauličnih udara najčešće se koristi metoda karakteristika, pomoću koje se parcijalne diferencijalne jednačine svode na obične diferencijalne jednačine [2].

$\mathrm{Na}$ tržištu postoji čitav niz specijalizovanih softvera za hidrauličku analizu cevovoda sa ili bez pojave hidrauličnog udara, na bazi numeričkih metoda, pomoću kojih se vrše proračuni i optimizacija sistema za zaštitu od hidrauličnog udara. Međutim, inženjerska intuicija, heuristička pravila i pojednostavljene projektantske preporuke su još uvek od velike važnosti za praktičnu upotrebu, bilo da je u pitanju izbor odgovarajućeg sistema za zaštitu od hidrauličnog udara ili njegovo dimenzionisanje. Nomogrami za izbor zapremine posude i dimenzionisanje cevnih priključaka se takođe mogu koristiti naročito od strane inženjera koji nemaju potrebno iskustvo kod projektovanja ovih sistema [3].

Numeričke analize mogu uzeti u obzir uticaj trenja unutar cevovoda, diskontinuitet $\mathrm{u}$ fluidnom toku, isparavanje fluida, brzinu porstiranja talasa, inerciju rada pumpe i uticaj različitih sistema za zaštitu od hidrauličnog udara.

U radu [4] autori su razmatrali efekat posude za sprečavanje hidrauličnog udara u pumpnoj stanici na potisnom cevovodu. Rezultati analize su pokazali da je zapremina posude ključni parametar koji određuje efektivnost zaštite od hidrauličnog udara. Maksimalni pritisak u sistemu opada sa povećanjem zapremine posude. Pri fiksiranoj zapremini posude, oblik posude i način montaže na cevovod (horizontalna ili vertikalna posuda) nema značajnijeg uticaja na pojavu prigušenja hidrauličnog udara. U cilju postizanja maksimalne efektivnosti zaštite, posuda treba da bude što bliže potisnom cevovodu pumpe.

Pojednostavljena analiza se može sprovesti rešavanjem diferencijalne jednačine za održanje količine kretanja za nestišljive fluide. Nagli prekid rada pumpe u cevovodu koji nije zaštićen nekim sistemom rezultuje naglim padom pritiska pri čemu udarni talas putuje uzvodno i nizvodno unutar cevovoda za određeno vreme. U slučaju cevovoda na koji su povezane posude za zaštitu od hidrauličnog udara oscilacije pritiska su znatno sporije i manje intenzivne. $U$ tom smislu teorija nestišljivog strujanja je ponekad dovoljna za analizu. Broj promenljivih koje je potrebno uzeti u obzir je značajno redukovan tako da se može primeniti uopštenija analiza u bezdimenzionalnoj formi pomoću koje se može izvršiti proračun zapremine posude i cevnih priključaka na relativno jednostavan način u nekoliko koraka.

\section{DIMENZIONISANJE ZAPREMINE POSUDE}

Autor Šašić [1] navodi da se posude pod pritiskom ili hidrofori najčešće koriste za cevovode prečnika do $\varnothing 600 \mathrm{~mm}$, a da je približna zapremina posude prema iskustvu $2 \%$ od ukupne zapremine cevovoda.

U radu [3] na osnovu rešavanja diferencijalnih jednačina količine kretanja za nestišljiv fluid za veći broj karakterističnih slučajeva izvedena je uopštena zavisnost bezdimenzione zapremine vazduha $\mathrm{u}$ posudi od minimalnog relativnog pritiska u sistemu.

$\mathrm{Na}$ osnovu teorije nestišljivog strujanja fluida može se napisati sledeća relacija

$$
h=-\frac{L}{g} \frac{d v}{d t}
$$

Jednačina se može integraliti kako bi se dobila potrebna zapremina fluida u posudi

$$
V_{w}=\frac{A L v_{0}^{2}}{2 g h}
$$

pri čemu je A - poprečni presek cevovoda $\left[\mathrm{m}^{2}\right]$, L - dužina cevovoda $[\mathrm{m}], v_{0}$ - brzina fluida u cevovodu pri stacionarnom stanju $[\mathrm{m} / \mathrm{s}], \mathrm{h}$ - prosečno smanjenje pritiska/napora u sistemu koje iznosi $\mathrm{h}=\mathrm{hmin} / 2[\mathrm{~m}]$ i g - ubrzanje Zemljine teže $\left[\mathrm{m} / \mathrm{s}^{2}\right]$.

U slučaju posuda sa malom zapreminom ekspanzija vazduha je približno adijabatska jer se gubici toplote kroz omotač mogu zanemariti. Kod sporijih ekspanzija u slučaju veće zapremine posude gubici toplote se ne mogu zanemariti pa je ekspanzija približno izotermska. Na osnovu Bojlovog zakona za izotermsku ekspanziju vazduha u posudi može se napisati

$$
V_{0} H_{0}=\left(V_{0}+V_{w}\right)\left(H_{0}-h_{\text {min }}\right)
$$

gde su:

$\mathrm{H}_{0}$ - početni apsolutni statički pritisak vazduha na zapremini $\mathrm{V}_{0}$ $\mathrm{u}$ posudi $[\mathrm{m}], \mathrm{V}_{\mathrm{w}}$ - početna zapremina fluida $\mathrm{u}$ posudi $\left[\mathrm{m}^{3}\right]$, a $\mathrm{h}_{\min }-$ najveće očekivano smanjenje pritiska vazduha u posudi [m].

Kombinacijom jednačina (2) i (3) dobija se potrebna zapremina vazduha u posudi $\mathrm{u}\left[\mathrm{m}^{3}\right]$ :

$$
V_{0}=\left(\frac{H_{0}}{h_{\min }}-1\right)\left(\frac{A L v_{0}^{2}}{2 g H_{0} \frac{h_{\min }}{2 H_{0}}}\right)
$$

ili

$$
V_{0}=\frac{H_{0}}{h_{\min }}\left(\frac{H_{0}}{h_{\min }}-1\right) \frac{A L v_{0}^{2}}{g H_{0}}
$$

Kombinacijom jednačina (3) i (5) dobija se jednačina za određivanje ukupne zapremina posude $\mathrm{u}\left[\mathrm{m}^{3}\right]$ :

$$
V=V_{0}+V_{\mathrm{w}}=\frac{H_{0}^{2}}{h_{\text {min }}\left(H_{0}-h_{\text {min }}\right)}\left(\frac{H_{0}}{h_{\text {min }}}-1\right) \frac{A L v_{0}^{2}}{g H_{0}}
$$

Prilikom analize nije uzet $\mathrm{u}$ obzir pad pritiska usled prigušnih elemenata i usled trenja u priključnom cevovodu i pretpostavljeno je da je ekspanzija gasa u posudi izotermska. Generalnija jednačina za ekspanziju gasa može da se napiše u sledećem obliku: 


$$
P_{0} V_{0}^{\mathrm{k}}=P V^{\mathrm{k}}
$$

gde su P - pritisak gasa a $\mathrm{k}$ - izložilac adijabate čija vrednost se kreće u opsegu $1 \div 1,4$ sa dva granična slučaja ( $\mathrm{k}=1$ u slučaju izotermske ekspanzije i k=1,4 u slučaju adijabatske ekspanzije). Treba napomenuti da je autor analizom osetljivosti dokazao da rezultati ne zavise $\mathrm{u}$ većoj meri od pretpostavljene vrednosti $\mathrm{k}$ [3].

\section{DIMENZIONISANJE CEVNIH PRIKLJUČAKA}

Maksimalni protok fluida iz posude je u trenutku zaustavljanja pumpe, tj. kada u posudi vlada radni (početni) pritisak. Pre nego što se strujanje vode u cevovodu uspori, pad pritiska na izlaznom priključku iznosi:

$$
h_{l}=K v_{e}^{2} / 2 g
$$

Pomoću jednačine kontinuiteta

$$
v_{e} D_{e}^{2}=v_{p} D_{p}^{2}
$$

konačno se dobija izraz:

$$
h_{l}=2 v_{0}^{2}\left(D_{p} / D_{e}\right)^{4} / 2 g
$$

Gde su K-koeficijent koji uzima u obzir otpore usled isticanja vode iz posude, uticanja vode u cevovod i gubitke usled trenja u cevnom priključku. Tipična vrednost ovog koeficijenta iznosi K=2 [3]. U jednačinama (8-10) indeks e se odnosi na izlazni cevni priključak a indeks $\mathrm{p}$ na glavni cevovod $\left(v_{p}=v_{0}\right)$. Dozvoljeni pad pritiska $\mathrm{u}$ glavnom cevovodu treba da bude manji od statičkog pritiska u cevovodu $\mathrm{H}_{0}$ kako bi se izbegla pojava vakuuma uzvodno u cevovodu. Stvarni dozvoljeni pad pritiska bi trebalo odrediti na osnovu konfiguracije cevovoda. Dozvoljeni pad pritiska koji će biti korišćen u ovom radu je $\mathrm{H}_{0} / 2$, tako da iz jednačine (10) sledi izraz za određivanje unutrašnjeg prečnika izlaznog cevnog priključka u [m]:

$$
D_{e}=D_{p}\left(2 v_{0}^{2} / g H_{0}\right)^{1 / 4}
$$

Iskustvene preporuke su da prečnik izlazne cevi treba da iznosi $25 \div 50 \%$ od prečnika glavnog cevovoda, $\mathrm{D}_{\mathrm{e}}=(0,25 \div 0,5) \mathrm{D}_{\mathrm{p}}$. U cilju sprečavanja abrazivnog dejstva fluida na cevni priključak preporučena brzina fluida u izlaznom cevnom priključku bi trebalo da bude manja od $10 \mathrm{~m} / \mathrm{s}$ [3].

Detalj tipičnog povezivanja posude na cevovod sa karakterističnim dimenzijama je prikazan na slici 1 .

Kod dimenzionisanja ulaznog cevnog priključka treba uzeti u obzir da fluid koji struji iz glavnog cevovoda sabija vazduh u posudi, čime se postepeno smanjuje brzina fluidnog toka. Maksimalni pritisak vazduha u posudi odgovara pritisku fluida u cevovodu u trenutku kada je njegova brzina jednaka nuli. Sa druge strane maksimalni pad pritiska (prigušenje) pri strujanju fluida u posudu je pri maksimalnoj brzini fluida u glavnom cevovodu. Kao što je ranije naglašeno, prigušenje pozitivno utiče na usporavanje brzine fluida u glavnom cevovodu, tako da je potrebna manja količina vazduha da bi se kompenzovao hidraulični udar. Generalno, pojava vakuuma u sistemu može izazvati više problema nego pojava prekomernog pritiska. Shodno tome dimenzija ulaznog cevnog priključka može biti relativno mala. Iskustvene preporuke su $10 \%$ od prečnika glavnog cevovoda ili kriterijum po kome pad pritiska u ulaznom cevnom priključku treba da bude 2,5 puta veći od pada pritiska u izlaznom priključku [3].

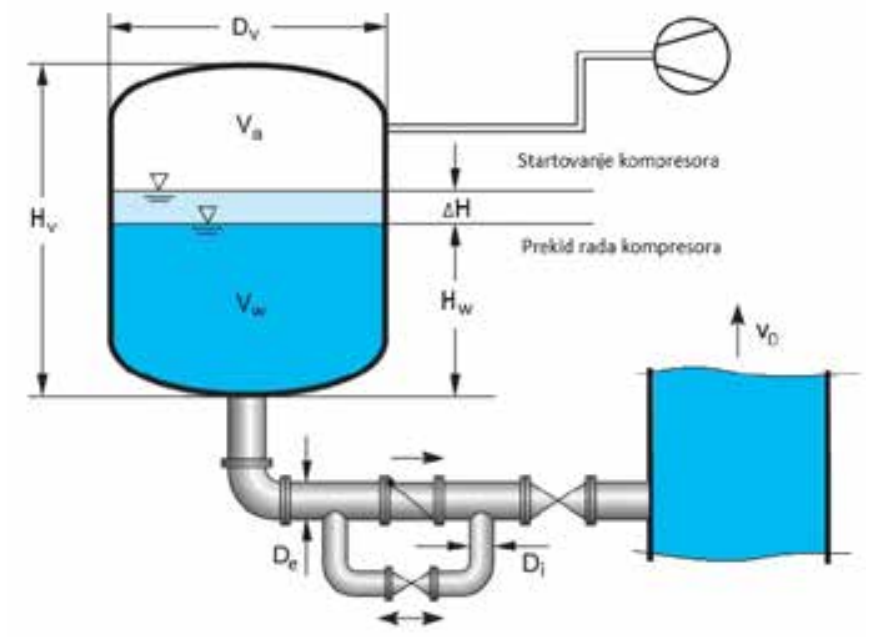

Slika 1: Detalj priključenja posude na cevovod sa karakterističnim dimenzijama [5]

Prilikom pojednostavljenog proračuna dimenzije ulaznog priključka pretpostavlja se da je zapremina gasa pri punoj ekspanziji dva puta veća od zapremine gasa u radnom stanju [3].

Primenom jednačine (1) može se napisati:

$$
d v=\frac{g h_{\min } T}{2 L}
$$

gde je T period u kome se odigrava prestrujavanje fluida u posudu.

Pod pretpostavkom da je

$$
V_{a} \approx 2 V_{0} \approx \frac{1}{2}\left(Q_{0} T\right)
$$

sledi

$$
T \approx \frac{2 V_{a}}{Q_{0}} \approx \frac{4 V_{0}}{Q_{0}}
$$

gde su $V_{a}$ - zapremina vazduha $\left[\mathrm{m}^{3}\right], V_{0}$ - početna zapremina vazduha $\left[\mathrm{m}^{3}\right]$ i $Q_{0}$ - početni protok fluida $\left[\mathrm{m}^{3} / \mathrm{s}\right]$

Uvrštavanjem izraza za T iz jednačine (14) u jednačinu (12) može se odrediti maksimalna povratna brzina fluida u glavnom cevovodu

$$
v_{r}=v_{0}-\frac{2 g h_{\text {min }} V_{0}}{Q_{0} L}
$$

Ako se maksimalni prirast pritiska u sistemu limitira na $10 \%$ od početnog statičkog pritiska u cevovodu 


$$
h_{\max }=0,1 H_{0}=\frac{2 v_{0}^{2}}{2 g}\left(\frac{D_{p}}{D_{i}}\right)^{4}
$$

sledi izraz za određivanje prečnika ulaznog cevnog priključka u $[\mathrm{m}]$ :

$$
\begin{aligned}
& D_{i}=D_{p}\left[\frac{10 v_{0}^{2}}{g H_{0}}\right]^{1 / 4}=D_{p} \\
& \text { U slučaju da je } \mathrm{h}_{\max } \text { prom } \\
& T \approx \frac{2 V_{a}}{Q_{0}} \\
& d v=\frac{g h_{\max } V_{a}}{L Q_{0}} \\
& V_{a}=\frac{A L V_{0}^{2}}{2 g h_{\max }} \\
& 2 \\
& D_{i}=D_{p}\left(\frac{v_{0}^{2}}{g h_{\max }}\right)^{1 / 4} \frac{1}{\sqrt{2}}
\end{aligned}
$$

Zapremina vazduha na atmosferskom pritisku često nije dovoljna da bi se obezbedila neophodna zapremina gasa kada je sistem pod pritiskom. Da bi se rešio ovaj problem, može se povećati ukupna zapremina posude ili obezbediti snabdevanje posude komprimovanim vazduhom što je uobičajen slučaj u praksi. Još jedno od mogućih rešenja je ugradnja posude za gasom koji je zarobljen u elastičnoj membrani. Membranu je potrebno nakon izvesnog vremena zameniti ali u ovom slučaju troškovi održavanja su značajno manji u poređenju sa sistemom sa vazdušnim kompresorima što čini ove posude naročito pogodnim za udaljene lokacije na magistralnim cevovodima [3].

U sistemima gde se može tolerisati pojava vakuuma na vrhu posude za zaštitu od hidrauličnog udara se može postaviti nepovratni ventil koji omogućava strujanje vazduha u posudu kod pojave vakuuma pri čemu se zarobljeni vazduh u posudi sabija kada se pojavi povratno strujanje fluida iz cevovoda u posudu.

\section{v. ZAKLJUČAK}

Posude pod pritiskom koji se obezbeđuje komprimovanim vazduhom su pogodna metoda za zaštitu cevovoda od negativnih pojava koje nastaju kao posledica hidrauličnog udara. Na osnovu jednačina koje su prikazane u radu, inženjeri na jednostavan način mogu da dimenzionišu posudu, odrede potrebnu zapreminu vazduha i dimenzije ulaznog i izlaznog cevnog priključka. Kao ulazni parametri koriste se dozvoljeni podpritisak i nadpritisak koji se mogu javiti u sistemu.

\section{PRAKTIČAN PRIMER}

Odrediti potrebnu zapreminu vazduha i ukupnu zapreminu posude za zaštitu cevovoda za transport vode od hidrauličnog udara pri čemu su unutrašnji prečnik cevovoda $\varnothing 900 \mathrm{~mm}$, dužina cevovoda 18 $\mathrm{km}$, apsolutni statički pritisak $410 \mathrm{~m}$ i brzina vode u stacionarnom stanju 1,4 m/s. Kao kriterijumi za izbor posude usvajaju se minimalni pritisak u sistemu koji iznosi $40 \%$ od inicijalnog statičkog pritiska i maksimalni pritisak u sistemu koji iznosi za $40 \%$ više od inicijalnog statičkog pritiska.

Najveće očekivano smanjenje pritiska u sistemu iznosi:

$\mathrm{h}_{\text {min }}=\mathrm{H}_{0}-\mathrm{H}_{\text {min }}=410-0,4 \cdot 410=246 \mathrm{~m}$

Najveće očekivano povećanje pritiska u sistemu iznosi:

$\mathrm{h}_{\max }=\mathrm{H}_{\max }-\mathrm{H}_{0}=1,4 \cdot 410-410=164 \mathrm{~m}$

Zapremina vazduha u posudi određuje se iz jednačine (5):

$\mathrm{V}_{0}=\frac{\mathrm{H}_{0}}{\mathrm{~h}_{\min }}\left(\frac{\mathrm{H}_{0}}{\mathrm{~h}_{\min }}-1\right) \frac{\mathrm{ALv}_{0}^{2}}{\mathrm{gH}_{0}}=\frac{410}{246}\left(\frac{410}{246}-1\right) \frac{0,9^{2} \cdot \pi \cdot 18000 \cdot 1,4^{2}}{4 \cdot 9,81 \cdot 410}$

$\mathrm{V}_{0}=6,2 \mathrm{~m}^{3}$

Ukupna zapremina posude određuje se iz jednačine (6):

$$
\begin{aligned}
V= & \frac{H_{0}^{2}}{h_{\min }\left(H_{0}-h_{\text {min }}\right)}\left(\frac{H_{0}}{h_{\min }}-1\right) \frac{A L v_{0}^{2}}{g H_{0}}= \\
& \frac{410^{2}}{246 \cdot(410-246)}\left(\frac{410}{246}-1\right) \frac{0,9^{2} \cdot \pi \cdot 18000 \cdot 1,4^{2}}{4 \cdot 9,81 \cdot 410}=1
\end{aligned}
$$

Unutrašnji prečnik izlaznog cevnog priključka određuje se iz jednačine (11):

$$
D_{e}=D_{p}\left(2 v_{0}^{2} / g H_{0}\right)^{1 / 4}=0,9 \cdot\left(2 \cdot 1,4^{2} /(9,81 \cdot 410)\right)^{1 / 4}=0,16 \mathrm{~m}
$$

Unutrašnji prečnik ulaznog cevnog priključka određuje se iz jednačine (21):

$$
D_{i}=D_{p}\left(\frac{v_{0}^{2}}{g h_{\max }}\right)^{1 / 4} \frac{1}{\sqrt{2}}=0,9 \cdot\left(\frac{1,4^{2}}{9,81 \cdot 164}\right)^{1 / 4} \cdot \frac{1}{\sqrt{2}}=0,12 \mathrm{~m} .
$$

\section{Literatura}

[1] Šašić, M., Transport fluida $i$ čvrstih materijala cevima, Naučna knjiga, Beograd, Jugoslavija, 1990.

[2] Bačelić Medić, Z., Zaštita pumpnog postrojenja od hidrauličnog udara, Završni rad, Sveučilište u Zagrebu, Fakultet strojarstva i brodogradnje, Zagreb, Hrvatska, 2010.

[3] Stephenson, D., Simple guide for design of air vessels for water hammer protection of pumping lines, Journal of Hydraulic Engineering, Vol. 128 (2002), 8, 2002.

[4] Wang, L., Wang, F. J., Zou, Z. C., Li, X. N., Zhang, J.C., Effects of air vessel on water hammer in high-head pumping station, 6th International Conference on Pumps and Fans with Compressors and Wind Turbines, IOP Conf. Series: Materials Science and Engineering, 52,2013

[5] ***, Water Hammer, KSB Know-how, Volume 1, www.ksb.com 